кн. изд-во, 1985. - 88 с.

6. Duggal J., Pankaj K, Tiwari B.N. Chemo-Pharmacological Aspects of Alfalfa // Journal of Advanced Scientific Research, 2011, Vol. 2(1), P. 50-53.

7. Rimi F., Macolino S., Ziliotto U. Relationships between dry matter yield, forage nutritive value, and some canopy parameters of alfalfa crop // Grassland in a changing world / Ed. H. Schnyder et al. Proceedings of the 23rd General Meeting of the European Grassland Federation, Kiel,
Germany, 29th August - 2nd September 2010, P. 548-550.

Попова Татьяна Николаевна, канд. с.-х. наук, научный сотрудник, Ершовская ОСОЗ НИИСХ ЮгоВостока. Россия.

413502, Саратовская обл., Ершовский р-н, пос. Тулайково.

Тел.: 89372681541.

Ключевые слова: люиерна; сорт; урожай зеленой массы; белок; клетчатка; коррелячия.

\title{
THE ANALYSIS OF ALFALFA VARITIES ON THE CONTENT OF FIBER AND CELLULOSE
}

Popova Tatyana Nikolaevna, Candidate of Agricultural Sciences, Researcher, Ershov Experimental Station "Agricultural Research Institute for South-East Region”. Russia.

Keywords: alfalfa: variety; total plant weight; fiber; cellulose; correlation.

The article generalized data for 2009-2015 under the content of fiber and cellulose on absolutely dry substance of alfalfa varieties (selected in Ershov Experimental Station). According to the results of researches of the fiber content the following data have been obtained:
Artemida, Diana, Sirena are 3 \% higher, Natali and Eruslanka are $8 \%$ higher, and Satellite is $13 \%$ higher than standard Uzen'. The cellulose content of Diana was $5 \%$ higher than Uzen'. The 5-year analysis of the given perspective populations and new variety Virineya has shown: fiber content of Virineya and a population $2 / 07$ is higher than the standard by $6 \%$, cellulose content was higher in a population 1/07. The interconnection and matrix of coefficients of correlation between a total plant weight and the content of fiber and cellulose in variety-standard Uzen' is shown.

\section{СРАВНИТЕЛЬНАЯ ОЦЕНКА ГИБРИДОВ УЛУЧШЕННОЙ ШАРОЗЁРНОЙ ПШЕНИЦЫ}

\author{
РОМАНОВ Борис Васильевич, Федеральный Ростовский аграрный научный центр \\ ПИМОНОВ Константин Игоревич, Донской государственный аграрный университет \\ СОРОКИНА Ирина Юрьевна, Донской государственный аграрный университет \\ КУРАСОВА Людмила Геннадиевна, Саратовский государственный аграрный университет \\ имени Н.И. Вавилова
}

В статъе представлены характеристики исходной шарозёрной пшенищы и улучшенной ее формы, а также выделенной макромутантной мягкой пшенищы. Показано, что более въсоким коэффициентом удельной продуктивности Куп $(0,96)$ отличалась мутантная мягкая пшеница, тогда как между улучшенной $(0,86)$ и исходной Шарадой $(0,88)$ различия по этому показателю практически отсутствовали. Масса зерна с колоса у улучшенной формы и макромутантной мягкой пшеницей на 1/3 больше, чем у исходной Шарады, что связано с проявлением вклада третьего элементарного диплоидного генома. Дана оценка влияния разных генотипов мягкой пшеницы на продукиионные показатели улучшенной шарозёрной пшеницы сорта Шарада. Для проверки влияния генотипов мягкой пщеницы на продуктивность Шарады улучшенной были проведены ее скрещивания с другими формами мягкой пшеницы. При гибридизаиии улучшенной Шарады с образиами мягкой пшеницы преимущество по продуктивности остается за гибридными формами типа мягкой пшеницы. Установлено, ито более высокая продуктивность мягкой пшеницы наследуется сцепленно. Сравнительный анализ гибридных форм комбинации: Шарада улучшенная $\times$ мягкая макромутантная пшеница показал, что превосходство вида мягкой пшеницы по массе зерна с колоса над шарозёрным видом сохраняется. Скрещивание улучшенной Шарады с близкородственной макромутантной мягкой пшенищей существенного повыщения продукиионных признаков первой не дало. Некоторое повышение массы зерна с колоса отмечается у шарозёрной улучшенной формы при скрещивании ее с генетически более отдаленной формой T. aеstivum.

Введение. Шарозёрная гексаплоидная пшеница Triticum sphaerococcum Perc. обладает рядом полезных свойств: устойчивостью к полеганию; эректоидным расположением листьев; нетребовательностью к почвенно-климатическим условиям; скороспелостью, жаровыносливостью, неосыпаемостью; обладает шаровидной формой зерновки, имеющей существенное значение для соотношения выхода муки и отрубей [4]. На базе одной из линий T. sphaerococcum при гибридизации с озимой мягкой пшеницей был создан сорт озимой шарозёрной пшеницы Шарада, урожайность которой составляет максимум 80-85 \% по сравнению с мягкой пшеницей [2].

Ранее нами установлено, что меньшая продуктивность T. sphaerococcum AABBDD по сравнению 
c T. aestivum AABBDD связана с отсутствием в ее продукционных признаках (в частности массы зерна с колоса) вклада одного из трех ее диплоидных геномов [7]. Следовательно, Шарада, как и все представители T. sphaerococcum, обладала «двухфеномным», а мягкая пшеница «трехфеномым» уровнем данного показателя. Попытки увеличить продуктивность шарозёрной пшеницы при гибридизации T. sphaerococcum с T. aestivum не увенчались успехом, потому, что в потомстве у растений со сферококкоидным типом зерновок масса 1000 зерен была значительно меньше, чем у растений с зерновками типа мягкой пшеницы [1]. Поскольку крупность и тип зерновок наследуются сцепленно, то получить крупнозерные сферококоидные формы, превосходящие представителей мягкой пшеницы, крайне затруднительно. Поэтому, учитывая, что в продукционных признаках Шарады не проявляется вклад одного из трех диплоидных геномов, под воздействием колхицина получена улучшенная ее форма, с трехфеномным уровнем массы зерна с колоса, которая тем не менее уступала по продуктивности мягкой пшенице $[3,8,9]$. В этой связи представляет значительный интерес воздействия разных генотипов мягкой пшеницы на продукционные показатели Шарады улучшенной.

Цель настоящей работы - оценить влияние разных генотипов мягкой пшеницы на продукционные показатели улучшенной шарозёрной пшеницы сорта Шарада.

Методика исследований. В опыте для оценки влияния генотипов мягкой пшеницы на продукционные характеристики Шарады улучшенной использовали метод гибридизации. Исследования проводились на опытном поле ФГБНУ ФРАНЦ (Донского зонального НИИСХ), почвы которого представлены черноземом обыкновенным. Поскольку улучшенная форма шарозёрной пшеницы сорта Шарада, обладает таким же, как и мягкая пшеница, трехфеномным уровнем продукционных показателей, то, соответственно, должна легче скрещиваться с образцами мягкой пшеницы. Для проверки влияния генотипов мягкой пшеницы на продуктивность Шарады улучшенной были проведены следующие скрещивания:

с близкородственной формой макромутантной мягкой пшеницей, одновременно выщепившейся с шарозёрной улучшенной из исходной Шарады, которая обладала хорошими качественными показателями;

с так называемым полным гомологом мягкой пшеницы Рассвет-1, полученным нами в результате воздействия на семена T. kiharae супермутагеном нитрозометилмочевиной (HMM) [5, 6]. При этом в качестве материнской формы использовали Шараду улучшенную.

Объектами исследования в опыте служили:

исходная шарозёрная пшеница сорта Шарада;

полученные из нее улучшенная и мутантная формы мягкой пшеницы;

сорт Рассвет - 1 (полный гомолог мягкой пшеницы);

гибриды $\mathrm{F}_{2}$ от вышеуказанных скрещиваний с улучшенной формой.

Все растения выращивали одновременно и в одинаковых полевых условиях. В полную спелость зерна проводили отбор растений для структурного анализа. При математической обработке данных использовали стандартные вычислительные программы Microsoft Excel.

Результаты исследований. Из данных, представленных в табл. 1, следует, что масса побегов улучшенной формы и макромутантной мягкой пшеницы существенно превосходят Шараду исходной формы и достаточно близки между собой. Аналогичная картина наблюдалась по весу колосьев с зерном и соответственно массе зерна с колоса, где четко отмечается преимущество Шарады улучшенной и макромутантной мягкой над исходной и близость между ними.

По числу колосков и зерновок наибольшими показателями выделялась Шарада улучшенная. Однако по массе зерна с колоса (2,05 г) она была на уровне мягкой, даже несколько уступая в абсолютном выражении (2,11 г). Достоверно более высоким коэффициентом удельной продуктивности $K_{\text {уп }}(0,96)$ отличалась мутантная мягкая пшеница, тогда как между улучшенной $(0,86)$ и исходной Шарадой $(0,88)$ различий по этому показателю практически нет. Коэффициент удельной продуктивности показывает соотношение между вегетативной и репродуктивной сферами побега растения. По-видимому, благодаря, в том числе и более высокому $K_{\text {уп }}$ мягкая пшеница получает преимущество по

Таблица 1

Продукционные показатели шарозёрной пшеницы сорта Шарада и полученных из нее мутантных форм, 2018 г.

\begin{tabular}{|c|c|c|c|c|c|c|}
\hline \multirow[b]{2}{*}{ Генотип } & \multirow[b]{2}{*}{$\begin{array}{c}\text { Масса побега } \\
\text { с колосом, г }\end{array}$} & \multirow{2}{*}{$\begin{array}{c}\text { Колос с } \\
\text { зерном, } \\
\Gamma\end{array}$} & \multicolumn{2}{|c|}{ Количество с колоса } & \multirow[b]{2}{*}{$\begin{array}{c}\text { Масса зерна } \\
\text { с колоса, г }\end{array}$} & \multirow[b]{2}{*}{ Куп } \\
\hline & & & $\begin{array}{l}\text { колосков, } \\
\text { шт. }\end{array}$ & $\begin{array}{l}\text { зерновок, } \\
\text { шт. }\end{array}$ & & \\
\hline Шарада исходная & 2,86 & 1,72 & 17,4 & 38,0 & 1,32 & 0,88 \\
\hline $\begin{array}{l}\text { Мягкая из Шарады (му- } \\
\text { тантная) }\end{array}$ & 4,31 & 2,71 & 17,9 & 40,9 & 2,11 & 0,96 \\
\hline $\begin{array}{l}\text { Шарада улучшенная } \\
\text { (мутантная) }\end{array}$ & 4,40 & 2,70 & 20,3 & 47,7 & 2,05 & 0,86 \\
\hline $\mathrm{HCP}_{05}$ & 0,75 & 0,44 & 1,3 & 6,6 & 0,36 & 0,14 \\
\hline
\end{tabular}


урожайности. Поскольку это предполагает более эффективный физиологический процесс по формированию зерна вегетативной массой мягкой пшеницы. У Шарады улучшенной $K_{\text {уп }}$ не увеличился по сравнению с исходной формой, а увеличение массы зерна с колоса у него прошло за счет пропорционального повышения массы всего побега. Таким образом, у него пропорционально увеличилась и вегетативная и генеративная части побега, тогда как у мягкой пшеницы достоверно увеличился и $K_{\text {утг }}$.

В то же время весьма показательно, что масса зерна с колоса у улучшенной формы на $1 / 3$ больше, чем у исходной Шарады, что связано, вероятно, с проявлением вклада третьего элементарного диплоидного генома [9]. Так разница между улучшенной и исходной формой $(2,05-1,32=0,73)$ составляет $36 \%$, или $1 / 3$, что является очередным фактом, доказывающим трехфеномный уровень массы зерна с колоса улучшенной формы Шарады, по сравнению с двухфеномным у исходной формы.

Сравнительный анализ гибридных форм комбинации (Шарада улучшенная $\times$ мягкая макромутантная пшеница) показывает, что превосходство типа мягкой пшеницы по массе зерна с колоса над шарозёрной формой остается (табл. 2,3 ). Однако, если в первой комбинации она достигает практически $(2,74-2,07=0,67) 25 \%$, то во второй комбинации всего лишь $(2,85-2,45=0,40)$ $14 \%$. При более близкородственных скрещиваниях (см. табл. 2), показатели шарозёрного гибрида $(2,07$ г) остаются практически на уровне исходной улучшенной формы (2,05 г), которая возделывалась в том же опыте на соседней делянке. Однако при скрещивании с более отдаленной формой (сорт пшеницы Рассвет-1) картина несколько другая: повысилась масса зерна с колоса не только у мягкой пшеницы, но и у шарозёрной формы, чего, в принципе, авторы и добивались.
Вероятно, вовлекая в гибридизацию генетические отдаленные от улучшенной Шарады генотипы мягкой пшеницы, можно повысить продукционные характеристики первой.

Вместе с тем следует признать, что генотип мягкой пшеницы имеет преимущество над шарозёрной формой, поскольку в обоих комбинациях масса зерна с колоса у гибридной мягкой пшеницы достоверно больше, чем у получившихся гибридов $\mathrm{F}_{2}$ шарозёрной формы. Такого наследования, когда шарозёрный гибрид по массе зерна с колоса превышает тип мягкой пшеницы, не происходит. По-видимому, и такой показатель как масса зерна с колоса также наследуется с типом мягкой пшеницы сцепленно. Поэтому не получается генотипов шарозёрной пшеницы с урожайностью мягкой и, наоборот, генотипов мягкой пшеницы с небольшой массой зерна с колоса, как у шарозёрных гибридных форм. Это возможно при кроссинговере, но, к сожалению, в проведенном опыте авторам не удалось выявить таких форм.

С другой стороны, желательно вовлекать в гибридизацию генотипы мягкой пшеницы с высоким $K_{\text {уп }}$, что также должно, по-видимому, благоприятно сказаться на продукционных возможностях Шарады улучшенной, т.е. попытаться повысить продукционные признаки шарозёрных форм в рамках их генетического потенциала при помощи увеличения их $K_{\text {уп }}$. Для этого нужно, вероятно, проводить скрещивания с генотипами обладающими высоким $K_{\text {уп }}$.

Заключение. Более высоким коэффициентом удельной продуктивности $K_{\text {уп }}(0,96)$ отличалась мутантная мягкая пшеница, тогда как между улучшенной $(0,86)$ и исходной Шарадой $(0,88)$ различий по этому показателю практически не выявлено. При гибридизации улучшенной Шарады с образцами мягкой пшеницы преимущество по продуктивности остается за гибридами типа

Таблица 2

Характеристика колосьев гибридных форм $\mathrm{F}_{2}$ комбинации (Шарада улучшенная $\times$ мягкая пшеница, выщепившаяся из Шарады)

\begin{tabular}{|c|c|c|c|c|}
\hline \multirow{2}{*}{$\begin{array}{c}\text { Вариант - } \\
\text { гибридные формы F } \text {, от скрещивания (Шара- } \\
\text { да улучшенная × мягкая пшеница из Шарады) }\end{array}$} & \multirow{2}{*}{$\begin{array}{c}\text { Длина колоса, } \\
\text { см }\end{array}$} & \multicolumn{2}{|c|}{ Количество } & \multirow{2}{*}{$\begin{array}{c}\text { Масса } \\
\text { зерновок, г }\end{array}$} \\
\hline & & колосков, шт. & зерновок, шт. & \\
\hline Шарозёрная форма & 6,9 & 20,7 & 46,7 & 2,07 \\
\hline Мягкая пшеница & 9,1 & 21,7 & 51,2 & 2,74 \\
\hline \multicolumn{4}{|c|}{$\mathrm{HCP}_{05}$} & 0,21 \\
\hline
\end{tabular}

Характеристика колосьев гибридных форм $\mathrm{F}_{2}$ комбинации (Шарада улучшенная $\times$ мягкая пшеница сорт Рассвет-1)

Вариант -

(гибридные формы $\mathrm{F}_{2}$ от скрещивания Шарада улучшенная $\times$ мягкая пшеница сорт Рассвет-1)

Шарозёрная форма

Мягкая пшеница (n)

\begin{tabular}{|c|c|c|c|}
\multirow{2}{*}{$\begin{array}{c}\text { Длина колоса } \\
\text { см }\end{array}$} & \multicolumn{2}{|c|}{ Количество } & \multirow{2}{*}{$\begin{array}{c}\text { Масса зерно- } \\
\text { вок, } \Gamma\end{array}$} \\
\cline { 2 - 3 } & $\begin{array}{c}\text { колосков, } \\
\text { шт. }\end{array}$ & зерновок, шт. & 2,45 \\
\hline - & 21,3 & 60,7 & 2,85 \\
\hline - & 20,5 & 61,5 & 0,39 \\
\hline
\end{tabular}


мягкой пшеницы. При скрещивании улучшенной Шарады с близкородственной макромутантной мягкой пшеницей существенного повышения продукционных признаков у шарозёрной формы не произошло. В то же время при гибридизации ее с генетически более отдаленной формой мягкой пшеницы наблюдается повышение массы зерна с колоса на 0,40 г.

\section{СПИСОК ЛИТЕРАТУРЫ}

1. Афанасьев П.Д. Наследственные формы и крупность зерна в скрещиваниях Triticum sphaerococcum Persiv. x T.aestivum L. // Сб. науч. тр. по прикл. бот., генет. и селекц. - 1985. - Т. 98 - С. 72 - 75.

2. Боровик А.Н. Селекция и возвращение в культуру исчезающих и редких видов пшеницы: шарозёрной (T.sphaerococcum Perc), полбы (T.dicoccum (Schrank.) Schubl.), твёрдой (T.durum Desf.), шарозёрной (Triticale shaerococcum) для деверсификации производства высококачественного зерна: дис. ... д-ра с.-х. наук. - Краснодар, 2016. - 49 с.

3. Липатова А.А., Садыгова М.К., Сергеев В.В. Технологический потенциал сортов яровой мягкой пшеницы селекции ФГБУ «Ершовская ОСОЗ НИИСХ Юго-Востока» // Аграрный научный журнал. - 2017. № 7. - C. 13-18.

4. Пшеницы мира: видовой состав, достижения селекции, современные проблемы и исходный материал / под ред. В.Ф. Дорофеева. - 2-е изд., перераб. и доп. - Л., 1987. - 559 с.

5. Романов Б.В. Новая форма гексаплоидной пшеницы или полный гомолог T. aestivum L. // Генетика. 1994. - Т. 30 (приложения). - С. 133.

6. Романов Б.В. Новая форма гексаплоидной пшеницы - гомолог T. aestivum L. // Новые и нетрадиционные растения и перспективы их использования: труды III Междунар. симпозиума. - Москва - ПущиHо, 1999. - T. 2. - С. 409-411.
7. Романов Б.В. Тетраплоидный уровень проявления сложных количественных признаков у некоторых гексаплоидных видов пшеницы // С.-х. биология. Сер. Биология растений. - 2011. - № 5. - С. 31-39.

8. Романов Б.В. Введение в феномогеномику количественных признаков рода Triticum. - Пос. Персиановский, 2010. - 136 с.

9. Романов, Б.В., Пимонов К.И. Феномогеномика продукционных признаков видов пшеницы. Пос. Персиановский, 2018. - 188 с.

Романов Борис Васильевич, канд. биол. наук, старший научный сотрудник лаборатории генетики и селекиии сельскохозяйственных растений, Федеральный Ростовский аграрный научный иенттр. Россия.

346735, Ростовская обл., Аксайский $p$-н, пос. Рассвет, ул. Институтская, 1.

Тел.: (8938) 155-69-01.

Пимонов Константин Игоревич, $\partial-p c$. $-x$. наук, проф., зав. кафедрой «Растениеводство и садоводство», Донской государственный аграрный университет. Россия.

Сорокина Ирина Юрьевна, канд. с.- $x$. наук, доиент кафедры «Растениеводство и садоводство», Донской государственный аграрный университет. Россия.

346493, Ростовская обл., Октябрьский р-н, пос. Персиановский, ул. Кривошлыкова, 24.

Тел.: (8950) 855-68-87.

Курасова Людмила Геннадиевна, канд. биол. наук, доцент кафедры «Растениеводство, селекиия и генетика», Саратовский государственный аграрный университет имени Н.И. Вавилова. Россия.

410012, г. Саратов, Театральная пл., 1.

Тел.: (8452) 26-16-28.

Ключевые слова: Шарада улучшенная; T. sphaeroсоссит; мягкая пшенииа; гибридизация; масса зерна с колоса; продукционные показатели.

\section{COMPARATIVE EVALUATION OF HYBRIDS OF IMPROVED T. SPHAEROCOCCUM PERC.}

Romanov Boris Vasylyevich, Candidate of Biological Sciences, Senior Researcher, Federal Rostov Agrarian Scientific Centre. Russia.

Pimonov Konstantin Igorevich, Doctor of Agricultural Sciences, Professor, Head of the chair "Crop Production and Gardening”, Don State Agrarin University. Russsia.

Sorokina Irina Yurievna, Candidate of Agricultural Sciences, Associate Professor of the chair "Crop Production and Gardening”, Don State Agrarin University. Russsia.

Kurasova Lyudmila Gennadievna, Candidate of Biological Sciences, Associate Professor of the chair "Crop Production, Selections and Breeding”, Saratov State Agrarian University named after N.I. Vavilov. Russia.

Keywords: Sharada improved; T. sphaerococcum; softwheat; hybridization; grain weight per spike; production indicators.

The article presents the characteristics of the original T. sphaerococcum Perc. and its improved form, as well as the selected macromutant soft wheat. It was shown that macromutant soft wheat differed by a higher coefficient of specific productivity Kup (0.96), whereas there was practically no difference between improved (0.86) and initial Sharada (0.88). The mass of grain per spike of an improved form and macromutant soft wheat is 1/3 more than that of the original Sharada. It is associated with the influence of the third elementary diploid genome. The effect of different genotypes of soft wheat on the production indicators of improved Sharada varieties is assessed. To test the effect of soft wheat genotypes on the Sharada improved productivity, we crossed it with other forms of soft wheat. When hybridizing Sharada improved with samples of soft wheat, hybrid forms of soft wheat are more productive. It is established that higher productivity of soft wheat is inherited concatenated. Comparative analysis of hybrid forms of the combination: Sharada improved $\times$ soft macromutant wheat showed that the superiority of the type of soft wheat by weight of grain per spike over the T. sphaerococcum Perc. is preserved. The crossing of Sharada improved with a closely related macromutant soft wheat did not significantly increase the production characteristics of the first. A slight increase in the grain mass per spike is observed in T. sphaerococcum Perc. when it is crossed with T.aestivum. 